\title{
A Graphics and Design Course Based on Competition Machine Development
}

\author{
Marek Kujath, Ted Hubbard, \\ Department of Mechanical Engineering, Dalhousie University, Halifax NS, \\ marek.kujath@dal.ca,ted.hubbard@dal.ca
}

\begin{abstract}
A second year mechanical engineering course in design and graphics is described. The course is structured around the design and fabrication of machines that take part in a competition at the end of the term; however, the main components of the students' performance evaluation are midterm and final design reports. The design objective is to build a competition machine, using only a supplied kit of materials, that performs a specified task better than the opponent's. The course instructor prepares a new contest each year. This paper outlines the course structure and contents. It details the competition organization and its physical setup. Challenges associated with teaching this type of design course are discussed as well.
\end{abstract}

\section{Introduction}

The second year Engineering Program at Dalhousie University includes the course MECH 2100, Engineering Design \& Graphics II. This course is a hybrid of two courses: ME 72, a contest based course taught at Caltech, and MECH 4020, the year-4 Senior Design Project taught at Dalhousie. MECH 2100 has been offered at Dalhousie for several years and the course format has successfully been exported to other universities. The course teaches the design process through a practical design project that culminates in a competition of student-built machines. The class is divided into teams of two; each team purchases a Design Kit containing various modeling materials and three model DC motors (see Figure 1). The competition is different each year, but the main items in the Design Kit stay the same.

Recent competitions included:

2001 - Snow Plow; plow as many balls as you can to your HOME (see Figure 2)
2002 - Ping-pong Ball Fountain; collect in your HOME as many balls as you can.

2003 - Sumo Wrestling; push your opponent off the arena (see Figure 3).

2004 - Lord of the Ring; retrieve the central ring and bring it $\mathrm{HOME}$ (see Figure 4).

The Mechanical Engineering faculty at Dalhousie has a strong conviction that design is the essence of engineering,therefore many courses have a strong design component. The objective of this paper is to present a successful design and graphics course that is based on competition machine development. This paper addresses the course's structure and contents, the performance evaluation of students, associated hardware and technical infrastructure, and encountered challenges.

\section{Course structure}

Dalhousie students have their first Engineering Design \& Graphics course (MECH 1100) in the first term of year-1 where they develop the skills of engineering free-hand sketching, 3D visualization, making and reading engineering drawings, and computer drafting. An integral part of this first engineering course at Dalhousie is a small design project (e.g. a small catapult), which is focused on the process of design and reporting.

In the second year, Dalhousie students take on a more ambitious design class: Engineering Design \& Graphics II (MECH 2100). This course revolves about a single design project, and the course structure and contents are tailored to help the students complete the project. The design, fabrication, and testing phases of the project itself mirror the twoterm Senior Design Project of the final year of the Mechanical Engineering Program at Dalhousie. 
The first half of the MECH 2100 consists of regular lectures and tutorials. The tutorials often involve group activities in groups of $6-8$ students. By the middle of the term the students have their machines designed and are ready for the first report. After the midterm reports are filed, the focus is on building the prototypes. Two weeks before the competition the prototypes are inspected, and after the inspection they are refined and further tested.

The students develop their competition machines in teams of two. The class is divided into design teams within the first week of the term. The students normally select their partners, but if they fail to form a team the instructor forms the team.

The course does not have a textbook, instead each team purchases a Design Kit previously prepared by the technical staff. The cost of the Kit per student is less than the cost of a text book. The major components of the Kit are three motors, electrical wiring, construction wood (popsicle sticks, dowels, rods, sticks, spools, disks, balsa, hardboard), paper and cardboard. There are many other small items as well; complete typical contents of the kit are listed in Appendix A and shown in Figure 1. A large variety of small parts are provided to encourage creativity and give many different possibilities for construction.

By far the most crucial parts of the Design Kits are the three motors. A wide range of motors will work, but they should operate at 3-6 Volts and have large gear reductions $(>20: 1)$ to provide sufficient torque. At Dalhousie, we have used several Tamiya models including the Hi-Speed (72002), Hi-Power (72003), Worm (72004) and 6-speed (72005) Motor Kits. All work well, but we have used the Hi-Power model more often than the others. Another useful Kit part is rubber tires. For vehicles, tire traction is very important to performance, and purchased tires such as Tamiya Sport Tires (70111) perform much better than student built tires.

A large component of the course is report writing including professional quality memos that are required every week, one memo per team. Typical topics of the memos are listed in Appendix C. Every student is required to keep an individual design notebook that contains an accurate record of the student's work. Team members typically receive the same mark on most assignments; the only major individual evaluation is for the design notebooks.

\section{Course Contents}

The competition between the developed machines is not the ultimate goal of the course, rather it is a practical means to teach the design process and design reporting.

The engineering design concept and the process of its implementation is introduced to the students at the beginning of the course. The design definition used in the course is similar to one proposed by Sheppard and Jenison [1]; the description of the design process is based on the standard five-step problem solving technique (see Appendix B).

The students are introduced to many aspects of the engineering design, i.e. stages of the design process, formal techniques of idea generation, assembly drawing, etc. Next, students are introduced to the basics of gearing, cable drives, large stroke mechanisms, clutches, model building, jointing, dc motors, concepts of power and efficiency, etc. The first practical assignments include: dissection of a simple mechanical device, assembly of geared motor sets, construction of Motor Testers, and construction of Mockup Models of the competition machines.

The students already know basic engineering graphics from their first year, in the discussed course the basics are reinforced and expanded by an introduction to solid modeling techniques and the standards of assembly drawings. The solid modeling introduction is done in a computer lab and takes about a week (approximately 6 contact hours).

Brainstorming is introduced as a formal technique of idea generation. To practice this technique the class is divided into groups of 68 students and the groups work on various topics. The initial topics are not directly related to their projects i.e. design a portable shelter for less than $\$ 50$, find alternate usage for a toothbrush, etc. Later in the course the brainstorming topics are related to the design projects i.e. competition strategies, defense modes, attack modes, locomotion methods, prototype major components, etc. An effort is made to ensure that the practice groups are different for each class so students learn to collaborate with people of different personalities.

For engineering dissection training each student receives an identical simple mechanical device (e.g. mechanical pencil, paper stapler, mechanical toy, etc.) at the beginning of a three-hour tutorial session. The dissection is first done individually, and later students work in groups of two. The dissection 
exercise is used to reinforce curiosity, learn the process of finding out how things work, exchange observations with others, learn how to report dissection, learn how to identify subassemblies, learn to name different subassemblies and components, label them and to make standard assembly and subassembly drawings. Numbering systems of assembly, subassembly, and part drawings are introduced as well. After the tutorial each design team prepares a memorandum in which they describe how the device works. In the text, references to the label numbers and assembly/subassembly numbers are made. The attached drawings are made by freehand in pencil, on separate letter-size sheets. The components are identified by numerical labels. The drawings contain part tables with each labeled component identified.

After the class is introduced to gears and dc motors, the students receive the first construction assignment requiring them to assemble 1 of 3 geared motors from the Kit according to the instructions provided with the Kit.

Subsequently, the students have their first design and construction exercise where they build a Motor Tester in the form of a two-wheel vehicle. The purpose of this assignment is to encourage the students to work with hardware and to instill in them confidence in their ability to design and build a working device. In addition, the purpose of this exercise is to test all motors, wiring, and the motion control. The task is to build a simple model of a twowheel vehicle, not necessarily the chosen competition design. Students are advised to wire temporarily all three motors with a connector box. They test the model's performance and demonstrate if they can control remotely the Model's motion on the floor; they demonstrate how the third motor turns as well. If the machinery does not work the first time, teams fix the wiring until it works.

Next, students build Mockup Models of their competition prototypes. The purpose of this exercise is to size the design, validate main concepts, and communicate the main idea of the design to the class. Students received the following tasks:

1. Collect building material (not from the Kit) for a Mockup Model such as cardboard, wire coat hangers, small pieces of wood, plastic, etc.

2. Build a full-scale mockup of your favorite design. Make the model as functional as the material permits. Mockup models, normally, do not contain motors, but they can be used. The features of the design should be set in true scale. Note: unlike a conceptual model, in a mockup model the true dimensions are important. The model's structure should be sturdy and the motion of its moving parts firmly constrained so the operation of the machine in all its functions i.e. defense/offense can be clearly demonstrated.

\section{Competition}

At the end of the previous academic year, a new competition is developed and new design kits are put together. An idea for a competition is considered good if the future contest has the following attributes: - is interesting,

- promotes a variety of designs,

- minimizes the chance of ties (has a score),

- has simple rules,

- allows a weak team to build a competitive device,

- promotes simple and reliable design solutions.

The competition takes place in a 4'x 4' arena, 6" off the ground (see Figure 5). Machines must start from their HOME positions: 12"x12" squares located in the diagonally opposite corners of the arena. At the start, machines must rest solely on the HOME squares and must fit into a 12" cube. During the competition, the electric power is turned on at the start and is shut off after 30 seconds to stop the machines. During the competition, machines are allowed to interfere with their opponents. Competitors have 1 minute before each match to prepare their devices, late machines are disqualified.

Only materials found in the Design Kit may be used for fabrication. Students may decide to interpret the rules creatively, but any device breaking the rules is impounded and does compete in the contest. Judges decisions are final.

Each machine is attached to a 6-conductor telephone overhead wire (the Kit contains a 6-conductor jack). Pedestal mounted controllers provide \pm 5 Volts to each motor (see Figure 5). The original controllers consisted of three DPDT switches. Recent competitions use one joystick with 4 SPDT relays plus two SPDT push buttons. Each machine has a Kill Switch (a standard 110V light switch), which the opponent can use to cut power to the device. The Kill Switch is located on the arena close to the HOME square so it can be defended at least initially. The contest arena, wiring, switches and electronics may not be altered in any way.

The competition normally requires the following support personnel: instructor; two judges controlling 
the contest and the sequence; two recorders recording and displaying the individual contest results, a shepherd controlling the student traffic, and two engineers/technicians supporting the electrical control and audiovisual equipment.

During the competition, students are advised to relax and have fun; they are encouraged to invite their friends to witness the event as well. The competition scene is normally crowded and noisy (see Figure 6), therefore announcements are made through loudspeakers. Two display screens are used: one is the scoreboard for displaying the results and the sequence of plays, the second displays live video of the competition arena. The competition sequence is as follows:

- every team plays twice during eliminations,

- the best 8 teams go to playoffs

(single elimination),

- the playoff sequence is:

8 teams --> 4 teams --> 2 teams --> winner,

- the winning team will have played five times.

- each win is worth one point on the term mark.

\section{Reporting}

Engineering reporting is the major component for evaluation of the students' performance and it includes:

- weekly memos

- midterm report

- final report

- poster and poster presentation

- web page.

Professional quality memos are required every week, one memo per team. Typical topics of the memos are listed in Appendix C, i.e. Requirements Definition, Morphological Chart, Mechanical Dissection and Assembly drawings, Inspection Prototype. Appendix D contains an example of requirements for a memo reporting the experience of building and testing the prototype for inspection.

The student teams write two design reports: Midterm and Final. Major components of the reports are engineering drawings: assembly, subassembly, and parts drawings. Typical contents of the reports are shown below:

\author{
Midterm Report Contents \\ 1 INTRODUCTION \\ 1.1 Background \\ 1.2 Objectives \\ 1.3 Requirements Definition \\ 2 PROBLEM EXPLORATION \\ 3 GENERATION OF ALTERNATIVES \\ 4 EVALUATION OF ALTERNATIVES \\ 5 DESIGN DESCRIPTION \\ 5.1 Detailed Description \\ 5.2 Competition Scenarios \\ 6 CONCLUSIONS \\ 7 REFERENCES \\ Appendix A: Contest Rules \\ Appendix B: Engineering Drawings
}

\section{Final Report Contents \\ 1 INTRODUCTION \\ 1.1 Background \\ 1.2 Objectives \\ 1.3 Requirements Definition \\ 2 INSPECTION PROTOTYPE \\ 3 COMPETITION PROTOTYPE \\ 4 SUMMARY OF DESIGN IMPROVEMENTS \\ 5 PERFORMANCE IN COMPETITION \\ 6 ANALYSIS AND DISCUSSION \\ 7 RECOMMENDATIONS AND CONCLUSIONS \\ 8 REFERENCES \\ Appendix A: Engineering Drawings \\ Appendix B: Calculations \\ Appendix C: List of unused Construction Materials \\ Appendix D: Photographs}

Before the competition a three hour poster session is organized during the tutorial period. The posters report the experience of developing, building, and testing the prototype. Each team prepares six poster pages (letter size) that are attached to a (24" x 36") poster board. The students are advised that the text, figures, drawings, photographs, tables, etc. should be readable from a distance of 10 feet. The poster design should be clean, crisp, professional, well organized, easy to read and eye appealing. The page assignment for the poster is provided in Appendix E. The posters are hung on the wall of the class in clusters of 46 and each student makes a 5 minutes presentation to students from the poster cluster. The presentations in the clusters run simultaneously. After the presentations a competition is held for the best poster in the class.

At the end of the term the teams submit an assembly drawing with a description of the design highlights 
for a web page as an another form of reporting; a sample of a submitted drawing is shown in Figure 7.

\section{Evaluation}

A team's performance is compared to the performance of the best teams in the class. Design projects are evaluated on the basis of several factors:

- written reports, memos, participation, etc.

- quality, originality, and efficiency of the design

- performance of the device at the competition.

The winner of the contest will not necessarily get the highest mark, nor does a poor showing in the contest necessarily mean a low mark. The evaluation of the students' performance is mainly based on the quality of engineering communication: memos, drawings, verbal and poster presentations, technical reports, etc. The prototype and the competition results constitute only a small fraction of the class evaluation: $10 \%$ and $5 \%$ respectively.

The evaluation of the report format considers the following:

- title page

- table of Contents

- report components e.g. Intro., Calculations, etc.

- references

- appendices

The evaluation of the design description considers the following:

- drawing quality

- d rawing clarity

- labels, pointers, etc.

- figure numbering and captions

- referencing of drawings in the text

- clarity of the description

- originality of the design

\section{Typical Grading Scheme}

$\begin{array}{lr}\text { Final Report } & 40 \% \\ \text { Mid-Term Report } & 15 \% \\ \text { Assignments/Quizzes } & 10 \% \\ \text { Prototype } & 10 \% \\ \text { Design Log Books } & 5 \% \\ \text { Contest } & 5 \% \\ \text { Poster Presentation } & 5 \% \\ \text { Participation } & 5 \% \\ \text { Memos } & 5 \% \\ \text { TOTAL } & 100 \%\end{array}$

\section{Facilities / Electronics}

Every year two identical arenas and control setups are built (see Figure 5): one for testing/practicing and one for the competition only.

A small design studio is available to students; it is equipped with basic hand tools for model building from wood, plastic, metal and wire. It has soldering equipment for electrical connections as well. The practicing arena is located in the design studio. A classroom is used for regular classes and tutorials and in addition it is used for other activities. The classroom has tables seating two students and they can be easily moved aside to make space for group activities and to place the test arena for demonstration by student teams of mockup models and inspection of prototypes. The classroom is used for presenting posters as well.

There are four main electrical systems : Wiring, Motor Controllers, Power Supplies and Timers.

Wiring: The Kits contain 3 Tamiya motor kits, each with a RE-260 motor that runs on 3-5 Volts. The normal current drawn by the motor is on the order of a few hundred milliamps, however when the motors are stalled, they will draw 1-2 Amps. Thus more than 5 Amps may be required at times. The arena is equipped with a gantry frame supporting two overhead control cables (6-conductor telephone wires) that attach to the competition machines. Each Kit contains a 6-conductor telephone jack with color coded wiring connections (see Figure 8). Telephone wires are typically $24 \mathrm{AWG}$ and six feet of wire has a resistance of approximately $1 \Omega$ (comparable to the motor). There is a substantial power loss from these cables. Therefore, thicker gauge wire should be used when possible and only the last six suspended feet should be telephone wire.

Motor Controllers: Each motor can be driven with a positive or negative voltage to reverse direction. The simplest control option is to use 3 DPDT switches, each controlling 1 motor allowing off, forward and reverse for that motor (see Figures $9 \& 10$ ). This is a good option for the initial year offering the course. Students however prefer the more intuitive feel of a joystick. Two of the motors are controlled by a pedestal mounted joystick as shown in Figure 11 (Happ Controls: Ultimate Joystick, 8-way, Model: 50-7608-20). Tank style steering is provided: pressing forward drives both wheels positive, backward drives both wheels negative. Pressing left drives the right wheel positive and the left negative, 
pressing right does the opposite. To obtain tank style steering, four 5V, SPDT, relays (the relays should have at least a 5 Amp rating) and eight diodes are used as shown in Figure 12. The remaining motor is controlled by two SPDT pushbuttons (Happ Controls : Ultimate Pushbutton, Model: 53-9200-11) providing positive/negative voltages.

Power supplies: The motors will run from $3 \mathrm{~V}$ batteries. This is a good option for the initial year offering the course. At least $2 \mathrm{D}$ cells could be used for each vehicle, however the batteries will have to be replaced frequently and the vehicles will be sluggish. A better option is to use $5 \mathrm{~V}$ power supplies to offset the cable resistive losses. This could be any off-the-shelf power supply capable of providing at least 2 Amps, e.g. a Camcorder power supply. At Dalhousie we have modified standard PC power supplies to produce $5 \mathrm{~V}$ at several amps. Note that PC power supplies require a constant load across 2 specific leads. Thus a power resistor $(>5 \mathrm{~W})$ must be permanently installed for the power supply to function properly; this will also require a large heat sink to prevent overheating. Note also that the $-5 \mathrm{~V}$ on PC power supplies should not be used as it only provides typically $<500$ milliamps.

Timers: Power is supplied to the vehicles for 30 seconds, and is then cut off. Power cut-off can be done manually with a switch. This is a good option for the initial year offering the course. Alternatively a darkroom timer can be used; these have a variable timer (1-60 seconds) and a built-in relay to turn on/off the power. At Dalhousie we have built a simple CMOS electronic timer using a 555 timer chip with a 3 second pulse period, connected to a 4017 decade counter, and then connected to a $110 \mathrm{~V}$ relay.

\section{Challenges}

There are several practical challenges to offering this type of course. The course requires a great deal of advance preparation and investment of instructor time prior to the course. In particular the Kits must be carefully chosen to provide a rich supply of parts without becoming too expensive. Parts have to be ordered several months in advance and then be subdivided into kits. For a class of 50 students (25 teams), this is a significant amount of work.

Another practical issue is Safety. It is important to provide students with a sufficient range of tools to build their project, but also ensure that they will be working safely. For Dalhousie this has meant no power tools, hand tools only, construction in supervised areas only and limited access to soldering equipment. Students must also be given lectures and training on safe and proper construction techniques.

There are also several academic challenges in offering this type of course. It is important that all students buy the design kits as early as possible but some students tend to wait as long as possible. It is difficult to convince students to record their work in the engineering notebooks. It is important that the teams start building as soon as possible, teams typically wait to decide on the design. In reporting it is important that the teams tie the written description to the drawings by referencing the labeled parts and subassemblies. Often the students see the written description and the drawings as separate parts. Students often do not see the importance of the structure of formal reports. Meeting deadlines is a big problem for some students as well.

\section{Concluding Rema rks}

The paper describes a second year Mechanical Engineering design and graphics course that is based on the design and fabrication of a machine that takes part in a competition at the end of the term. The course requires a lot of planning and coordination of events: new competition event and associated arena each year, group activities in class, poster session, and final competition. The course also requires a great deal of work from the students in the design and the construction of their devices. However students find the course very rewarding.

The authors would like to acknowledge the assistance of Reg Peters, Greg Jollimore, Stewart Carr, Peter Jones and Dr. Adam Bell.

\section{References}

[1] Sheppard, S. and Jenison, R., "Thoughts on Freshman Engineering Design Experiences", Proceedings, Frontiers in Education Conference, Nov. 6-9, 1996, Salt Lake City, Utah.

\section{Appendix A: Typical Design Kit Contents}

\begin{tabular}{|c|l|r|}
\hline 1 & TAMIYA, hi-power motor, 72003 & 2 \\
\hline 2 & TAMIYA, worm gear motor, 72004 & 1 \\
\hline 3 & TAMIYA, sport tires, 70111 & 1 \\
\hline 4 & TAMIYA, pulley set, 70141 & 1 \\
\hline
\end{tabular}




\begin{tabular}{|c|c|c|}
\hline 5 & Hardboard 1/8" x 12" x 12" & \\
\hline 6 & balsa 1/2" x 1/2" x 12" & \\
\hline 7 & Popsicle sticks (medium) & 50 \\
\hline 8 & Popsicle sticks (large) & 40 \\
\hline 9 & Wooden rods, $12 "$ x 1/8" & 10 \\
\hline 10 & Wooden rods, 12 " x 1/4" & \\
\hline 11 & wooden dowels, 3" & \\
\hline 12 & wooden spools & \\
\hline 13 & wooden disks & \\
\hline 14 & Telephone jack, 6 conductor & \\
\hline 15 & Battery holder (AA not incl.) & \\
\hline 16 & Battery connector & \\
\hline 17 & Alligator clips & \\
\hline 18 & Speaker wire, 22 gauge, 2 cond. (ft) & \\
\hline 19 & Cable ties & \\
\hline 20 & Clothespins & \\
\hline 21 & Magnets (1/2" diameter) & \\
\hline 22 & Vinyl mini-blind slats (8 short, 4 long) & \\
\hline 23 & $1 / 4-20$ bolts - $1-1 / 4 "$ & \\
\hline 24 & $1 / 4$ - 20 nuts & \\
\hline 25 & Washers, 1/4" & 12 \\
\hline 26 & 4-40 bolts 1" & 12 \\
\hline 27 & $4-40$ bolts $1 / 2^{\prime \prime}$ & - \\
\hline 28 & $4-40$ nuts & 1 \\
\hline 29 & Blue foam sheets, 8.5x11" & \\
\hline 30 & O/H plastic sheets, $8.5 \times 11 "$ & \\
\hline 31 & Binder Clips (small 3/4") & \\
\hline 32 & Binder Clips (large 1-1/4") & \\
\hline 33 & Paper Clips (small) & \\
\hline 34 & Paper Clips (large - 2") & \\
\hline 35 & Springs & \\
\hline 36 & Small plastic container & \\
\hline 37 & Straws & \\
\hline 38 & Rubber bands (small - 1/16x2-1/2") & \\
\hline 39 & Rubber bands (medium - 1/8x3-1/2") & \\
\hline 40 & Rubber bands (large - 1/4×3-1/2") & \\
\hline 41 & Zip lock bags (small - 18x20 cm) & \\
\hline 42 & Zip lock bags (large $-27 \times 28 \mathrm{~cm}$ ) & \\
\hline 43 & Ping pong balls & \\
\hline 44 & $35 \mathrm{~mm}$ film canisters & \\
\hline 45 & Fishing line (6 feet) & \\
\hline 46 & Small dia. Plastic tubing (1 foot) & \\
\hline 47 & CD ROM's & \\
\hline 48 & Metal jar lids & \\
\hline
\end{tabular}

\begin{tabular}{|l|l|r|}
\hline 49 & File folders & 2 \\
\hline 50 & Cardboard box (for storage only) & 1 \\
\hline
\end{tabular}

\section{Appendix B: Engineering Design}

Engineering design is the systematic, intelligent generation and evaluation of specifications for artifacts whose form and function achieve stated objectives and satisfy specified constraints. The purpose and motivation for engaging in engineering design are (real or perceived) human needs. The outcome of the design process is often fabrication specifications, and the creation and production of a physical artifact.

DESIGN PROCESS (in five steps)

\section{Define and structure the design problem}

Engineering problems are typically open-ended, under-defined, ambiguous, and they have many solutions, therefore the designer has to define the problem in technical terms first:

Organize and plan the design process. Determine scope (what is/isn't included). Set Boundaries ( $\mathrm{min} / \mathrm{max}$ size, weight, speed, durability, functionality, etc.)

Identify Constraints ( cost, technology, timeline, personnel, etc.)

\section{Explore, gather and generate information}

Typically, engineering problems provide incomplete information therefore the designer has to first determine what data is missing and then, either find it or generate it in terms of estimates:

Estimate and make assumptions

Reverse engineering ( dissection)

Market Analysis

Interviews, internet, libraries

3. Generate a large number of alternatives

Alternatives can be generated by Creativity

Stimulation Techniques:

brainstorming

trigger-word techniques,

morphological chart techniques,

check list techniques

\section{Evaluate promising alternatives}

Consider ethics, safety, and aesthetics

Analyze value: economics, impact on society and environment 


\section{Implement}

Validate by numerical simulation and physical models

Make engineering calculation of critical components

Develop a fabrication plan and build a prototype

Test, modify, improve, and fine tune

Generate supporting documentation

\section{Appendix C: Typical Topics of Memos}

1 Requirements Definition

2 Morphological Chart

3 Dissection and Assembly drawings

4 Design Selection Chart

5 Conceptual Design

6 Mockup Model

7 Transmittal memo of the Midterm Report

8 Construction Status

9 Inspection Prototype

10 POSTER instead of Memo

11 Transmittal memo of the Final Report

\section{Appendix D: Inspection Prototype Memo Requirements}

Deliverables: Memo reporting the experience of building and testing the prototype: In your memo, please address the following points, in the same order as listed, and using the same item numbering:

\section{Properties of your device:}

a) list the pros

b) list the cons

\section{Operation of your device:}

a) Does your device work?

b) What works well?

c) What didn't work as well as planned? Why?

d) What are your biggest concerns about the competition?

3. Complete the sentences about the construction:

a) Things were going great until ...

b) Our first mistake was ...

c) If we were starting the construction again ....

4. Briefly critique your team's performance:

a) Describe the successes of working as a team.

b) Describe the problems of working as a team.

\section{Time}

What is the estimated amount of time that it took to build your prototype?

6. Advice to a novice:

What advice would you give to someone who was going to build a prototype machine in this class?

\section{Suggestions:}

Suggest what other important question(s) you could have been asked.

\section{Appendix E: Poster Page Assignment}

Page-1 TITLE, team number, Authors.

Page-2 (first half): Abstract.

Page-2 (second half) to Page-6 (first half): design objectives, development of the prototype, properties and operation of the device.

Page-6 (second half): Conclusions in a bullet form: test results, what works what does not, etc.

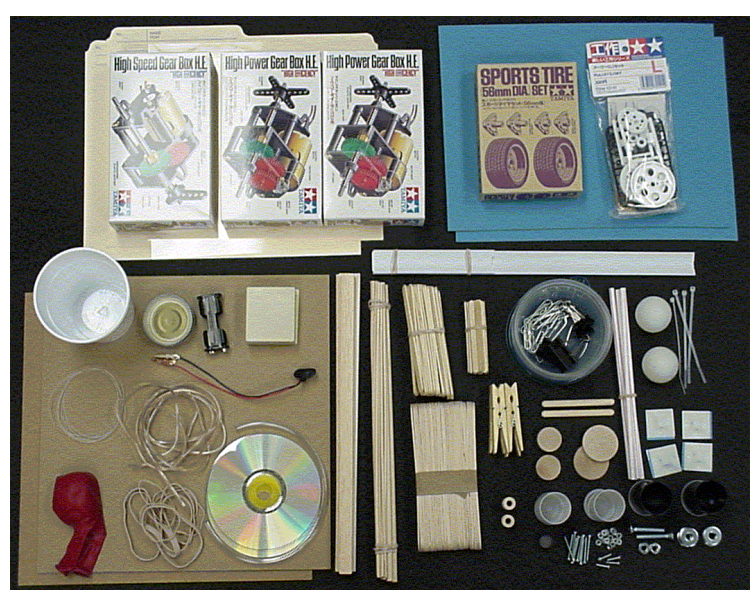

Figure 1: Design Kit contents (2002).

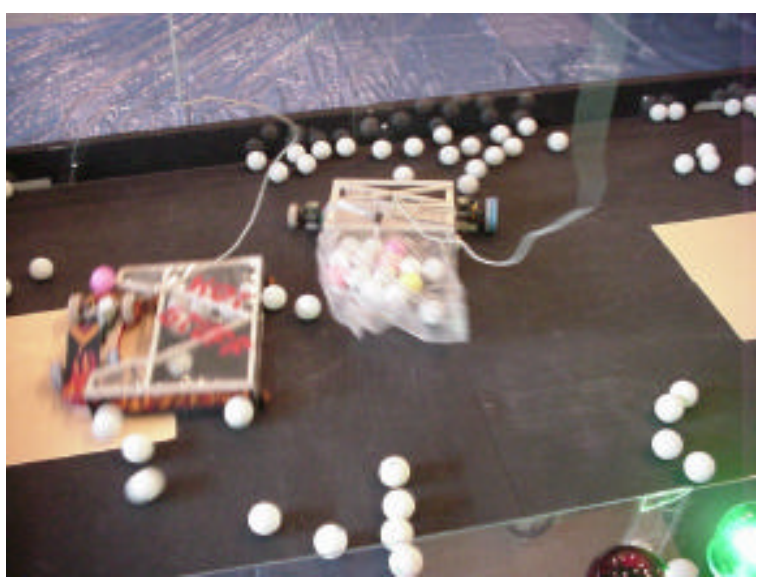

Figure 2: PingPong Ball Snowplow competition (2001). 


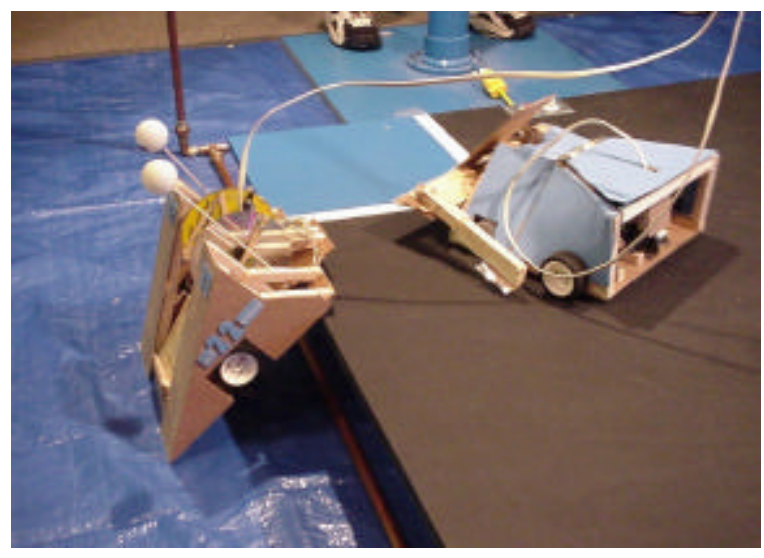

Figure 3: Sumo competition (2003).

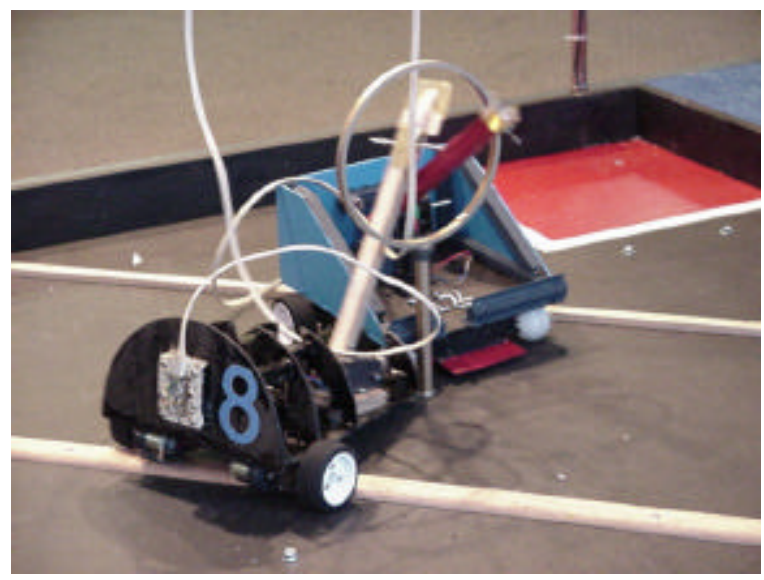

Figure 4: Lord of the Ring competition (2004).

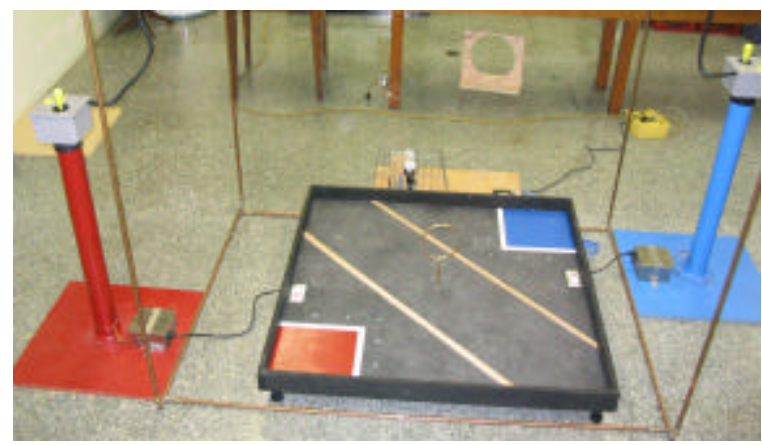

Figure 5: Arena, joystick pedestals, and wiring gantry for Design \& Graphics II (2004).

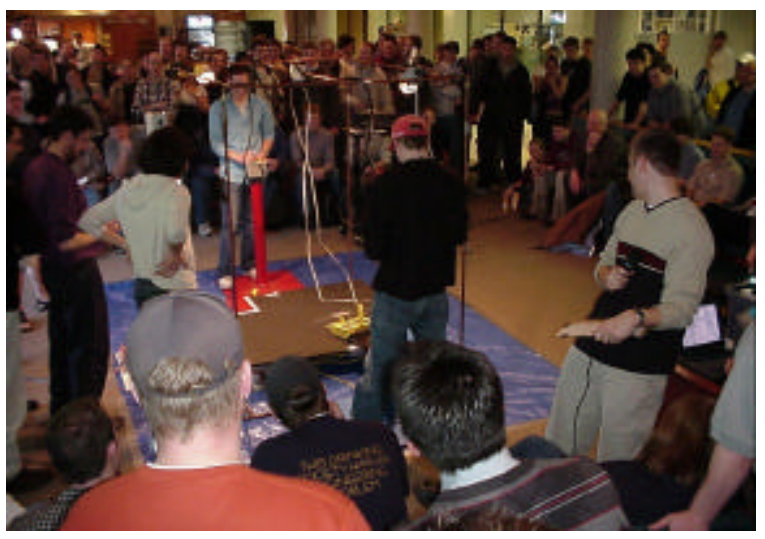

Figure 6: Competition day (2003).

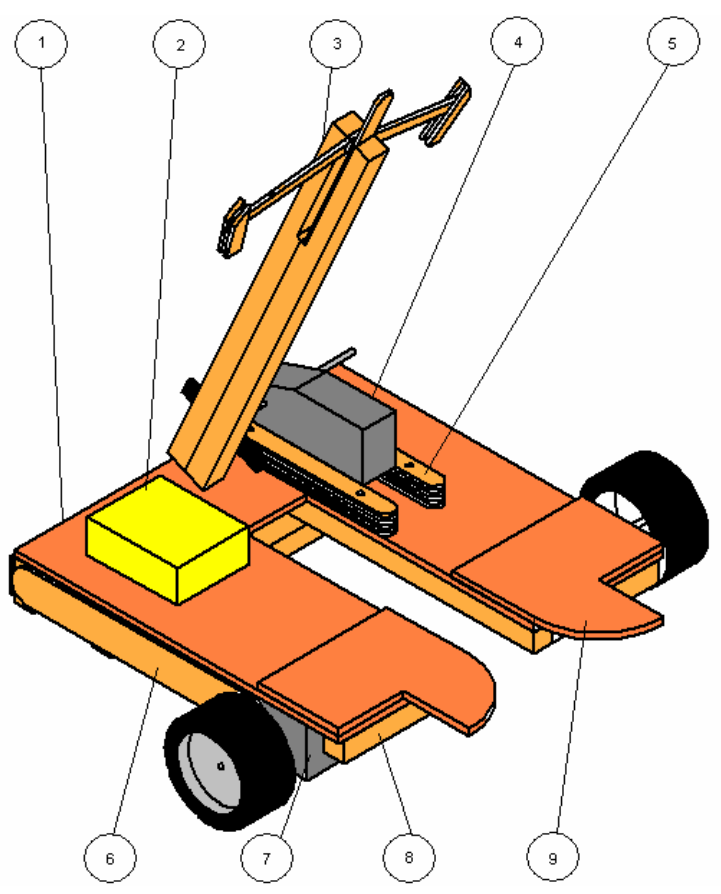

Figure 7: Sample assembly drawing: "The Flying Camel" design components and features: 1-Frame, 2-Cable Box, 3-Arm Assembly, 4-Arm Motor, 5-Popsicle Stick Risers, 6-Siding, 7-Drive Train, 8-Balsa Undercarriage, 9-Guides (Designed by Team \#5 in 2004: Chris Little and Jonathan Matheson). 


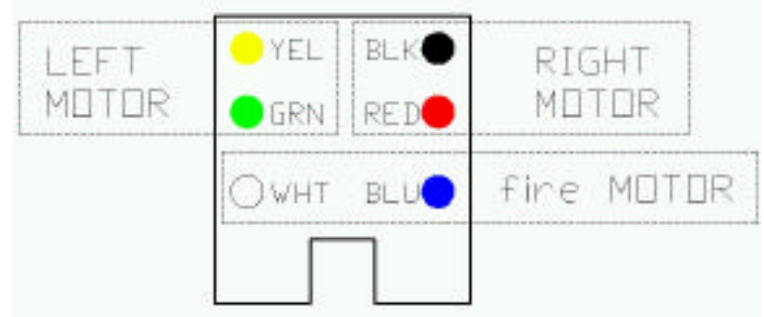

Figure 8: Six conductor telephone jack, supplied in Design Kits.

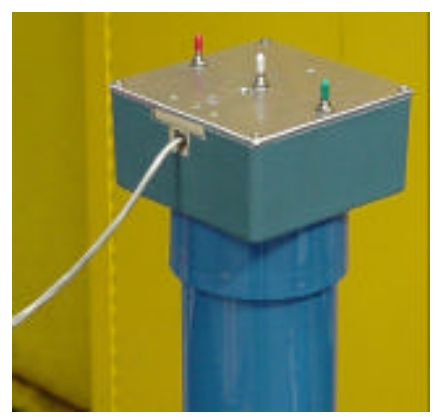

Figure 9: Original DPDT switch controller.

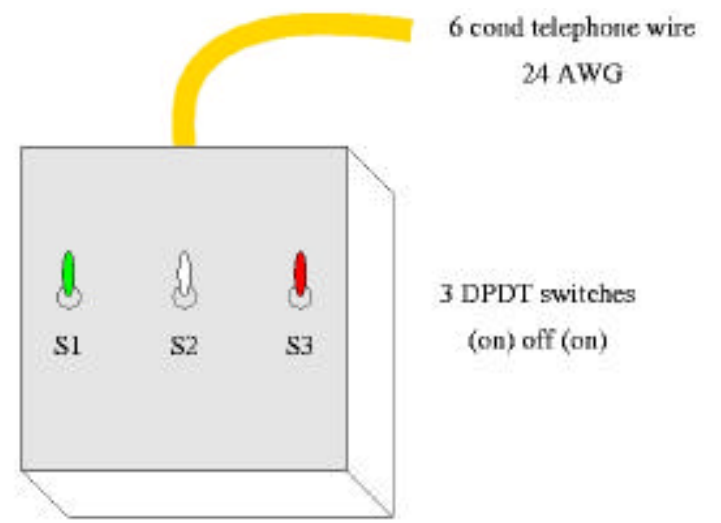

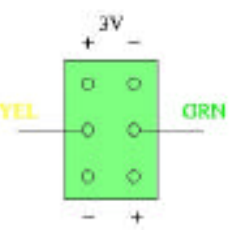

S 1

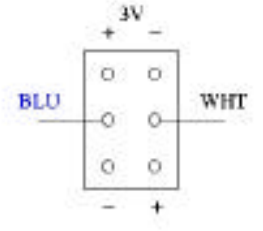

S2

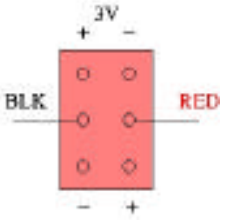

S3
Figure 10: Basic 3x DPDT switch controller circuit diagram.

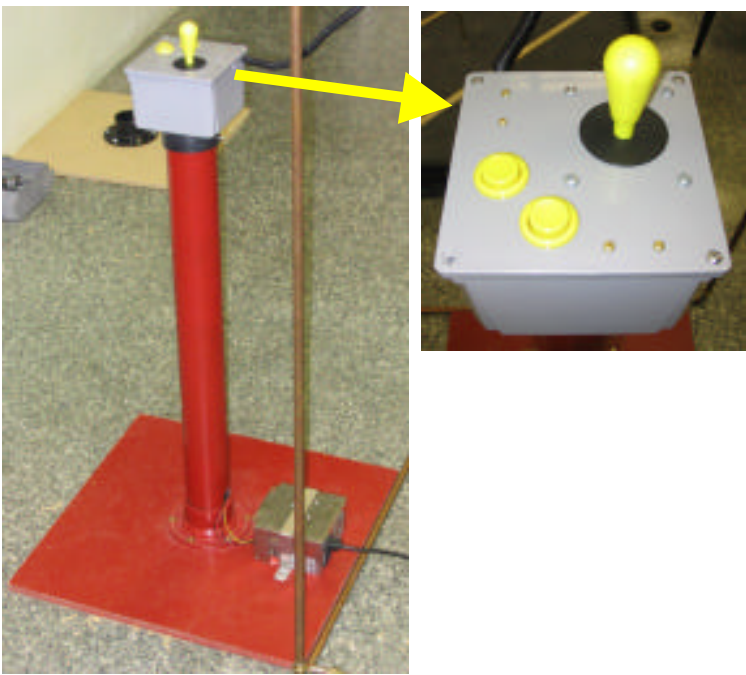

Figure 11: Pedestal mounted joystick controller with PC power supply at base.

SPDT

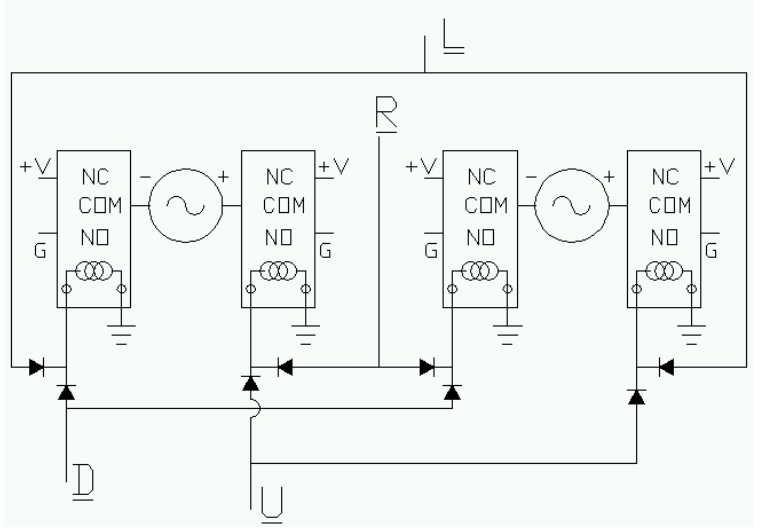

Figure 12: Joystick circuit diagram for tank steering. Parts: 1 Joystick ( $L=$ Left, $R=$ Right, $\mathrm{D}=$ Down, $\mathrm{U}=\mathrm{Up}), 8$ diodes and 4 relays $(5 \mathrm{~V}$, SPDT). 